University of Nebraska - Lincoln

DigitalCommons@University of Nebraska - Lincoln

USDA Wildlife Services - Staff Publications

U.S. Department of Agriculture: Animal and Plant Health Inspection Service

2009

\title{
Physiological Stress Response of Captive White-Tailed Deer to Video Collars
}

\author{
Remington Moll \\ University of Missouri, Columbia, Department of Fisheries and Wildlife Sciences \\ Joshua J. Millspaugh \\ University of Missouri, Columbia, joshua.millspaugh@umontana.edu \\ Jeff Beringer \\ Missouri Department of Conservation, Conservation Research Center \\ Joel Sartwell \\ Missouri Department of Conservation, Conservation Research Center \\ Rami Woods \\ University of Missouri, Columbia, Department of Fisheries and Wildlife Sciences
}

See next page for additional authors

Follow this and additional works at: https://digitalcommons.unl.edu/icwdm_usdanwrc

Part of the Environmental Sciences Commons

Moll, Remington; Millspaugh, Joshua J.; Beringer, Jeff; Sartwell, Joel; Woods, Rami; and VerCauteren, Kurt C., "Physiological Stress Response of Captive White-Tailed Deer to Video Collars" (2009). USDA Wildlife Services - Staff Publications. 962.

https://digitalcommons.unl.edu/icwdm_usdanwrc/962

This Article is brought to you for free and open access by the U.S. Department of Agriculture: Animal and Plant Health Inspection Service at DigitalCommons@University of Nebraska - Lincoln. It has been accepted for inclusion in USDA Wildlife Services - Staff Publications by an authorized administrator of DigitalCommons@University of Nebraska - Lincoln. 


\section{Authors}

Remington Moll, Joshua J. Millspaugh, Jeff Beringer, Joel Sartwell, Rami Woods, and Kurt C. VerCauteren 


\title{
Physiological Stress Response of Captive White-Tailed Deer to Video Collars
}

\author{
REMINGTON J. MOLL, Department of Fisheries and Wildlife Sciences, University of Missouri, 302 Natural Resources Building, Columbia, MO \\ 65211, USA \\ JOSHUA J. MILLSPAUGH, ${ }^{\mathbf{1}}$ Department of Fisheries and Wildife Sciences, University of Missouri, 302 Natural Resources Building, Columbia, MO \\ 65211, USA \\ JEFF BERINGER, Missouri Department of Conservation, Conservation Research Center, 1110 S College Avenue, Columbia, MO 65201, USA \\ JOEL SARTWELL, Missouri Department of Conservation, Conservation Research Center, 1110 S College Avenue, Columbia, MO 65201, USA \\ RAMI J. WOODS, Department of Fisheries and Wildlife Sciences, University of Missouri, 302 Natural Resources Building, Columbia, MO 65211, USA \\ KURT C. VERCAUTEREN, United States Department of Agriculture, Animal and Health Plant Health Inspection Service, Wildlife Services, National \\ Wildlife Research Center, 4101 LaPorte Avenue, Fort Collins, CO 80521, USA
}

\begin{abstract}
Animal-borne video and environmental data collection systems (AVEDs) are an advanced form of biotelemetry that combines video with other sensors. As a proxy for physiological stress, we assessed fecal glucocorticoid metabolite (FGM) excretion in 7 white-tailed deer (Odocoileus virginianus) fitted with AVED dummy collars; 9 additional deer served as controls. We collected fecal samples over 32 -week periods: pretreatment, treatment, and posttreatment periods. There were no differences in FGMs across time periods $\left(F_{2,218}=1.94, P=0.147\right)$ and no difference between FGMs of control and treatment individuals $\left(F_{1,14}=0.72, P=0.411\right)$. Fecal glucocorticoid metabolite excretion in AVED-collared deer was indistinguishable from uncollared animals and within the normal, baseline range for this species. Absence of an adrenal response to collaring suggested that AVED collaring does not induce physiological stress in deer. (JOURNAL OF WILDLIFE MANAGEMENT 73(4):609-614; 2009)
\end{abstract}

DOI: $10.2193 / 2008-266$

KEY WORDS adrenocortical response, animal-borne video and environmental data collection systems, Odocoileus virginianus, stress hormones, temperature, video collar, white-tailed deer.

Over the past 30 years, technological advancements have changed ecological research, both in available field and analytical methods and in the research questions that can be answered (Read and Clark 2006). New technologies make it possible to collect data that were previously impossible or impractical to obtain. For example, satellite telemetry has recently been used to map large-scale animal movements (i.e., $>1,000 \mathrm{~km}$ ) that can provide geographical scale for international management of wide-ranging endangered species (e.g., leatherback turtles [Dermochelys coriacea] in the Atlantic Ocean; Hays et al. 2004). Due to reductions in size and cost, sophisticated animal-borne sensors are becoming increasingly common tools for ecological research (Cooke et al. 2004, Ropert-Coudert and Wilson 2005).

Animal-borne video and environmental data collection systems (AVEDs; Moll et al. 2007) are an advanced form of biotelemetry that can combine video with a variety of sensors (e.g., Global Positioning System [GPS], audio, accelerometer; $\mathrm{He}$ et al. 2008). In addition to location information, these systems offer video from the animal's perspective. Applications of AVEDs are widespread, including investigations into animal behavior (Heithaus et al. 2002), foraging tactics (Davis et al. 1999), predator-prey interaction (Heithaus and Dill 2002), mate selection (Passaglia et al. 1997), behavioral energetics (Williams et al. 2000), and food selection (Beringer et al. 2004). Whereas early AVED research focused on elusive aquatic species (e.g., Marshall 1998), terrestrial systems have been recently

${ }^{1}$ E-mail: MillspaughJ@missouri.edu developed for both mammals (Beringer et al. 2004) and birds (Rutz et al. 2007). Despite their technological sophistication, AVEDs are still constrained by the fundamental assumption that underlies all animal-borne instrumentation: tagged animals are assumed to behave in the same manner as nontagged animals (White and Garrott 1990).

In addition to examining this assumption, evaluating animal response to animal-borne tagging is crucial to ensure ethical and humane treatment of research subjects (Minteer and Collins 2005, Wilson and McMahon 2006). Often, institutional animal care and use committees require researchers to justify potential impacts by demonstrating that techniques either do not harm study subjects or that the best available techniques are being used (Wilson and McMahon 2006). Despite the abundance of studies implementing animal-borne tags (e.g., radiotelemetry studies), assessments of their effects are uncommon and have produced mixed results (Withey et al. 2001).

Animal-borne tags are assumed to have negligible effects on large animals (Withey et al. 2001). However, deleterious effects have been reported for several large animals, including moose (Alces alces) calves (Swenson et al. 1999) and mountain goat (Oreamnos americanus) kids (Côté et al. 1998). Brooks et al. (2008) showed that even small changes in the weight and fit of tags might cause behavioral responses in large mammals. Because AVEDs are larger and heavier than traditional animal-borne tags, it is important to ensure that they do not induce adverse behavioral and physiological impacts, even on large animals. Further, the 
fine-scale video data collected by AVEDs might be more subject to bias from subtle tag effects than would coarser behavioral data (e.g., broad-scale movement data) collected by traditional animal-borne tags (Brooks et al. 2008). It is especially important to undertake evaluations of AVED effects due to their high-profile use on species of conservation concern (Moll et al. 2007).

As a proxy for physiological stress, we assessed fecal glucocorticoid metabolite (FGM) excretion in white-tailed deer (Odocoileus virginianus) fitted with AVED dummy collars. Stress hormone assessment is a useful tool for evaluating effects of animal-borne tags (e.g., Creel et al. 1997, Wells et al. 2003, Rittenhouse et al. 2005, Schulz et al. 2005) because it quantifies subtle changes in animal physiology (i.e., adrenal activity) rather than behavioral or demographic effects, which often only result after individual FGM levels remain high for sustained periods (Millspaugh and Washburn 2004). Previous FGM research has reported short-term effects from attached transmitters $(<24 \mathrm{hr}$; Wells et al. 2003), demonstrating the technique can detect acute stressors associated with attaching animal-borne tags. Our objective was to determine whether FGM levels differed between control deer and deer fitted with an AVED.

\section{METHODS}

We conducted our study at the United States Department of Agriculture/Animal and Plant Health Inspection Service/ Veterinary Services outdoor captive animal facility, located on the Colorado State University Foothills Research Campus in Fort Collins, Colorado, USA. Seventeen white-tailed deer $(8 \mathrm{M}, 9 \mathrm{~F})$ were housed in 4 adjacent approximately $40-\mathrm{m}^{2}$ pens separated by $2.5-\mathrm{m}$-tall dividers consisting of wood paneling and woven mesh wire. All individuals were 2 years old and hand-raised in captivity from birth; male deer were castrated. Four weeks prior to the study, we randomly assigned deer to pens; 3 pens housed 4 deer $(2 \mathrm{M}, 2 \mathrm{~F})$ each and one pen housed 5 deer $(2 \mathrm{M}, 3$ F). Pens were located within an approximately $850-\mathrm{m}^{2}$ exercise yard into which we periodically released the animals; during our study large snowdrifts in the yard limited animal release to approximately once every 2 weeks. We provided water, commercial deer chow, and hay ad libitum throughout the study. Our work was approved by the University of Missouri Animal Care and Use Committee (Protocol 4302).

We collected one fresh ( $<10$-min-old) fecal sample, which consisted of all pellets from a given defecation event, from each deer each day during 3 treatment periods: 1) pretreatment, from 29 January to 14 February 2007, during which no animals wore dummy AVEDs, 2) treatment, from 15 February to 28 February 2007, during which treatment individuals wore dummy AVEDs, and 3) posttreatment, from 1 March to 14 March 2007, during which no animals wore dummy AVEDs. Thus, treatment deer wore AVEDs for 2 weeks, a typical time of deployment for terrestrial, store onboard AVEDs (He et al. 2008). Within each sex we randomly assigned individuals to the control or treatment group to obtain 9 control $(5 \mathrm{~F}, 4 \mathrm{M})$ and 8 treatment subjects (4 F, $4 \mathrm{M}$ ). We assumed castrated male FGM levels would be similar to intact females (Chao and Brown 1984), as has been reported in other mammals (e.g., Graham and Brown 1996). During our study, we euthanized one female treatment individual due to injuries sustained during a fall and excluded her data from the analysis.

Given that time of day might affect FGMs in mammals (e.g., Touma et al. 2003), fecal sampling began at the same time each day (approx. $0700 \mathrm{hr}$ ) and concluded when we obtained one sample from each individual (usually before $1000 \mathrm{hr}$ ). After manually homogenizing the entire fecal mass of each collected sample (Wasser et al. 1996, Millspaugh and Washburn 2003), we placed it in a cooler with ice packs and transported it to an on-site freezer kept at $-15^{\circ} \mathrm{C}$ within 15 minutes of sample collection (Wasser et al. 2000, Millspaugh et al. 2002).

We handled all animals in a chute system after morning sampling on 14 February 2007 and fitted treatment individuals with dummy AVEDs. System components for dummy AVEDs were the same dimensions, weight, and configuration as true white-tailed deer AVEDs (Moll 2008) but did not contain electronic system components (e.g., video camera, microphone). Dummy AVEDs consisted of leather neck collars (width approx. $10 \mathrm{~cm}$ ) with affixed plastic weighted boxes; all collars weighed $1.4-1.5 \mathrm{~kg}$, constituting $2-4 \%$ of the subject deer's body weight (Fig. 1). We handled all animals in the chute system again after morning sampling on 28 February 2007 and removed dummy AVEDs.

At the end of the 6-week sampling period, we shipped all frozen fecal samples overnight to the University of Missouri for FGM analysis. We assayed samples from every third day of collection, which resulted in sufficient sample sizes for white-tailed deer FGM levels (Millspaugh and Washburn 2003); of the first 3 days, we randomly selected 31 January 2007 (i.e., the third day of sampling) to begin the sequence.

We followed sample preparation procedures described by Millspaugh et al. (2002) and extracted FGMs using a modified form of Schwarzenberger et al. (1991) described by Wasser et al. (2000). We used an $\mathrm{I}^{125}$ corticosterone radioimmunoassay kit (MP Biomedicals, Solon, $\mathrm{OH}$ ) to quantify FGMs. These procedures were previously validated by Millspaugh et al. (2002) for white-tailed deer. Inter-assay variation for 5 assays was $5.1 \%$ and average intra-assay variation for 20 random samples was $1.7 \%$.

We compared FGM levels between treatment and control animals across periods using PROC MIXED in SAS (SAS Institute 2004), treating individual deer as random effects. We used the REPEATED statement to accommodate repeated measures of FGM from the same individual and modeled 3 covariance structures, including compound symmetry, unstructured, and autoregressive structures (Littell et al. 1998). We used Akaike's Information Criterion with a sample size correction $\left(\mathrm{AIC}_{c}\right)$ to select the best model for covariance structure. We used the autoregressive 


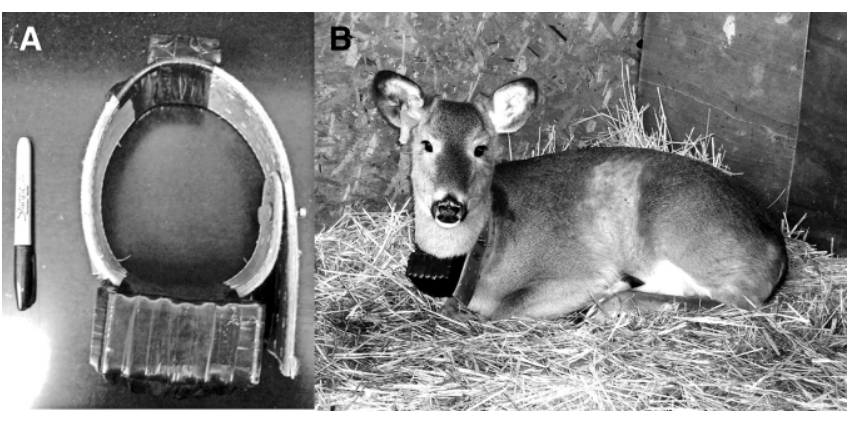

Figure 1. (A) Front view of the animal-borne video and environmental data collection system (AVED) dummy collar, consisting of a leather neck collar with attached weights and (B) a captive male white-tailed deer wearing an AVED dummy collar while bedded at the United States Department of Agriculture/Animal and Plant Health Inspection Service/Veterinary Services outdoor captive animal facility in Fort Collins, Colorado, USA, during January-March 2007.

covariance structure, which was the best covariance model by $6.1 \mathrm{AIC}_{c}$ units over the compound symmetry model (Littell et al. 1998).

Because FGMs in ungulates might be influenced by air temperature (e.g., Millspaugh et al. 2001), we performed a mixed effects linear regression analysis in the program $R(R$ Development Core Team 2004) to quantify effects of temperature on captive white-tailed deer FGMs. Assuming a 24-hour lag time between a stressful event and an associated FGM increase in white-tailed deer (Millspaugh et al. 2002), we coupled each FGM sample with the temperature 24 hours prior to collection ( $\pm 5 \mathrm{~min}$; Colorado Climate Center 2007).

\section{RESULTS}

Despite fluctuations in FGM levels throughout our study, there was no effect of dummy AVEDs on captive whitetailed deer FGM levels when compared with FGM levels of control animals $\left(F_{1,14}=0.72, P=0.411\right.$; Fig. 2$)$. Also, there was no difference between FGMs across periods $\left(F_{2,218}=\right.$ 1.94, $P=0.147)$ and no interaction between treatment and period $\left(F_{2,218}=0.51, P=0.602\right)$. Most importantly, none of the FGM values we observed were indicative of high values for white-tailed deer when compared with values from an adrenocortocotropin challenge (i.e., FGM values of $>60 \mathrm{ng} /$ g; Millspaugh et al. 2002). The largest change in mean FGM levels from one sampling interval to the next was a 7.3 $\mathrm{ng} / \mathrm{g}$ mean increase across all deer (11.1 ng/g to $18.4 \mathrm{ng} / \mathrm{g}$ ), which coincided with deer handling and the beginning of the treatment period (Fig. 2). This increase was also associated with a $12.9^{\circ} \mathrm{C}$ decrease in mean temperature (from $1.7^{\circ} \mathrm{C}$ to $-11.2^{\circ} \mathrm{C}$ ).

There was a negative relationship between air temperature and FGMs (slope $-0.062, t=-3.66, \mathrm{SE}=0.0 .17, \mathrm{df}=221$, $P<0.001$ ); as temperature decreased, FGMs increased and vice versa. For example, a $12.9^{\circ} \mathrm{C}$ decrease in mean temperature (from $1.7^{\circ} \mathrm{C}$ to $-11.2^{\circ} \mathrm{C}$ ) from 11 February to

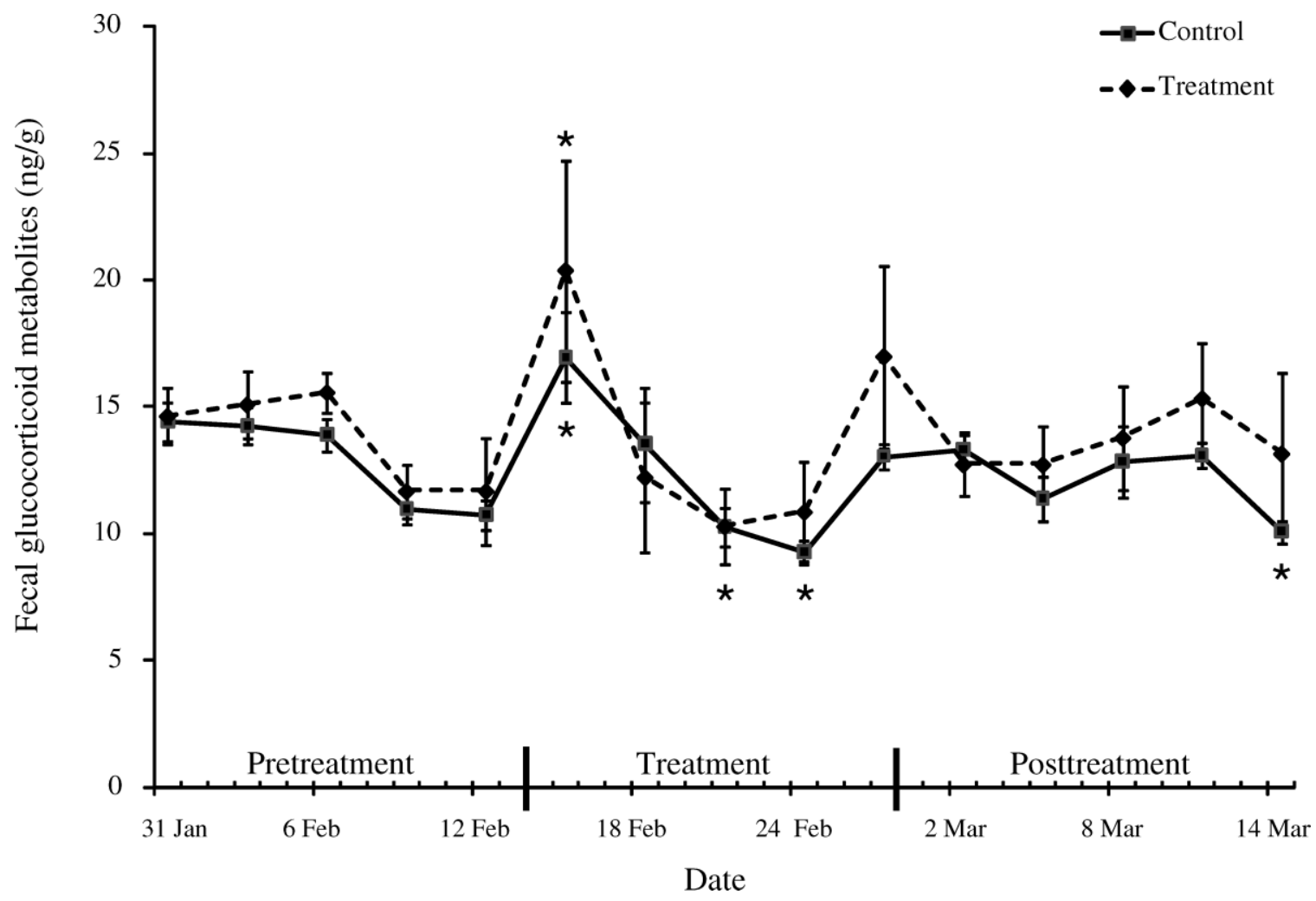

Figure 2. Fecal glucocorticoid metabolite (FGM) levels of captive white-tailed deer in control $(n=9)$ and treatment $(n=7)$ groups during pretreatment, treatment, and posttreatment periods at the United States Department of Agriculture/Animal and Plant Health Inspection Service/Veterinary Services outdoor captive animal facility in Fort Collins, Colorado, USA, during January-March 2007. Significant differences between pretreatment (baseline), treatment, and posttreatment FGM levels and are denoted with asterisks $(P<0.5)$. Error bars show one standard error. 
14 February 2007 was associated with a $7.3 \mathrm{ng} / \mathrm{g}$ increase in mean FGMs (from $11.1 \mathrm{ng} / \mathrm{g}$ to $18.4 \mathrm{ng} / \mathrm{g}$ ).

\section{DISCUSSION}

Similar to many other studies assessing the impact of animal-borne tags on large terrestrial mammals, we found no impact to deer, as measured by FGMs, from tagging. For example, radiocollars worn for $>1$ year did not affect behavior of female alpine chamois (Rupicapra rupicapra; Nussberger and Ingold 2006) or survival of juvenile guanacos (Lama guanicoe; Bank et al. 2000). Similarly, vaginal radiotags did not affect reproductive output in white-tailed deer (Bowman and Jacobsen 1998) or elk (Cervus elaphus; Johnson et al. 2006). In contrast, Swenson et al. (1999) observed decreased survival of moose calves with affixed ear transmitters and Côté et al. (1998) reported a decline in mountain goat kid survival due to increased abandonment by mothers immobilized and fitted with radiocollars. Brooks et al. (2008) observed that, while foraging, plains zebras (Equus burchelli) wearing GPS collars weighing $0.6 \%$ body mass had a $>50 \%$ lower travel rate compared to zebras fitted with collars weighing $0.4 \%$ of body mass. The range of effects reported by these studies for a diversity of large terrestrial species highlights the need to conduct species- and tag-specific evaluations of animalborne tags. When possible, physiological measures should be coupled with behavioral, body condition, and demographic measures for a complete assessment of impacts.

Fecal glucocorticoid metabolite assessments provide realtime, objective measures of adrenal responsiveness to acute or chronic stressors. The absence of between-group differences in FGM excretion suggests that AVED collars weighing $\leq 4 \%$ of individual body mass and worn $\leq 2$ weeks do not induce a physiological stress response in captive white-tailed deer. Other FGM evaluations have shown no effects of attached transmitters on a variety of species, including African wild dogs (Lycaon pictus; Creel et al. 1997), three-toed box turtles (Terrapene carolina; Rittenhouse et al. 2005), and mourning doves (Zenaida macroura; Schulz et al. 2005). Wells et al. (2003) observed a spike in FGMs following attachment of transmitters in dickcissels (Spiza americana) that returned to baseline levels within 1 day. We observed a similar spike across both treatment and control animals following handling on 14 February 2007 (Fig. 2). However, this spike coincided with the largest temperature decline during our study (a $12.9^{\circ} \mathrm{C}$ decrease over 3 days) and therefore might have been a temporary reaction to low temperatures.

The negative relationship between FGMs and air temperature might have been driven by several large fluctuations $\left(>10^{\circ} \mathrm{C}\right)$ in temperature over short periods (i.e., $\leq 3$ days) that were associated with an inverse change in FGMs (e.g., when temp decreased, FGMs increased). A similar relationship between stress hormones and acute air temperature changes (i.e., changes within 3 days) has been reported in birds (e.g., Romero et al. 2000, Frigerio et al. 2004). Our data suggested that FGM levels of captive white-tailed deer in Colorado are low during winter. Low levels of FGMs in winter have also been reported for white-tailed deer in Texas (Chao and Brown 1984) and Missouri (Millspaugh et al. 2002). In contrast, Bubenik et al. (1983) reported a peak in cortisol during winter for captive white-tailed deer in Ontario, Canada. In our study, production of glucocorticoids by deer in response to sudden changes in temperature is likely an adaptive, normal response to cold temperatures.

Overall, the excreted measures we observed were within the normal range excreted by undisturbed deer and lower than levels documented following pharmacological hormone challenge (Millspaugh et al. 2002), which suggested that FGM levels of $>60 \mathrm{ng} / \mathrm{g}$ were outside the normal range of values. Our study animals wore AVEDs for 2 weeks, which was longer than most AVED deployments (Moll et al. 2007). Physical effects and chronic stress from wearing tags for longer periods should be considered for longer studies. We observed some neck abrasion from the AVED collars; efforts should be made to ensure good fit of neck collars and pads or inflation tubes should be considered for heavier tags (Krausman et al. 2004).

\section{Management Implications}

We found AVEDs weighing $\leq 4 \%$ of individual body mass did not increase FGM levels of captive white-tailed deer during a 2-week deployment. Therefore, a captive deer's stress response to wearing an AVED should not bias data collection under these conditions. Our study suggested that temperature elicited a stronger physiological stress response than AVEDs and similar studies should be conducted during periods of high temperature. As AVED technology improves and recording life increases, managers should assess AVED effects on animal behavior and physiology for longer durations and consider additional metrics such as body weight and behavior for a comprehensive assessment of impacts.

\section{Acknowledgments}

We thank T. Ruby, H. Kinsell, M. Lavelle, N. Seward, J. Fischer, M. McCollum, K. Held, V. Moll, J. Davis, and M. Meier for help with sample collection and animal care and handling and C. Rittenhouse and R. Gitzen for assistance with statistical analysis. This work was supported in part by the National Science Foundation under grant DBI0529082. We also thank the University of Missouri, the Missouri Department of Conservation, and the United States Department of Agriculture/Animal and Plant Health Inspection Services/Wildlife Services/National Wildlife Research Center for supporting our research. We thank G. Hall and 2 anonymous reviewers for comments that improved this manuscript.

\section{LITERATURE CITED}

Bank, M. S., W. L. Franklin, and R. J. Sarno. 2000. Assessing the effect of radiocollars on juvenile guanaco survival. Oecologia 124:232-234.

Beringer, J., J. J. Millspaugh, J. Sartwell, and R. Woeck. 2004. Real-time video recording of food selection by captive white-tailed deer. Wildlife Society Bulletin 32:648-654. 
Bowman, J. L., and H. A. Jacobson. 1998. An improved vaginal-implant transmitter for locating white-tailed deer birth sites and fawns. Wildlife Society Bulletin 26:295-298.

Brooks, C., C. Bonyongo, and S. Harris. 2008. Effects of global positioning system collar weight on zebra behavior and location error. Journal of Wildlife Management 72:527-534.

Bubenik, G. A., A. B. Bubenik, D. Schams, and J. F. Leatherland. 1983. Circadian and circannual rhythms of LH, FSH, testosterone (T), prolactin, cortisol, T3 and T4 in plasma of mature, male white-tailed deer. Comparative Biochemistry and Physiology: A, Comparative Physiology 76:37-45.

Chao, C. C., and R. D. Brown. 1984. Seasonal relationships of thyroid, sexual and adrenocortical hormones to nutritional parameters and climatic factors in white-tailed deer (Odocoileus virginianus) of south Texas. Comparative Biochemistry and Physiology: A, Comparative Physiology 77:299-306.

Colorado Climate Center. 2007. Fort Collins weather station. < http://ccc. atmos.colostate.edu/ autowx/>. Accessed 20 Nov 2007.

Cooke, S. J., S. G. Hinch, M. Wikelski, R. D. Andrews, L. J. Kuchel, T. G. Wolcott, and P. J. Butler. 2004. Biotelemetry: a mechanistic approach to ecology. Trends in Ecology and Evolution 19:334-343.

Côté, S. D., M. Festa-Bianchet, and F. Fournier. 1998. Life-history effects of chemical immobilization and radiocollars on mountain goats. Journal of Wildlife Management 62:745-752.

Creel, S., N. M. Creel, and S. L. Monfort. 1997. Radiocollaring and stress hormones in African wild dogs. Conservation Biology 11:544-548.

Davis, R. W., L. A. Fuiman, T. M. Williams, S. O. Collier, W. P. Hagey, S. B. Kanatous, S. Kohin, and M. Horning. 1999. Hunting behavior of a marine mammal beneath Antarctic fast ice. Science 283:993-996.

Frigerio, D., J. Dittami, E. Möstl, and K. Kotrschal. 2004. Excreted corticosterone metabolites co-vary with ambient temperature and air pressure in male Greylag geese (Anser anser). General and Comparative Endocrinology 137:29-36.

Graham, L. H., and J. L. Brown. 1996. Cortisol metabolism in the domestic cat and implications for non-invasive monitoring of adrenocortical function in endangered felids. Zoo Biology 15:71-82.

Hays, G. C., J. D. R. Houghton, and A. E. Myers. 2004. Pan-Atlantic leatherback turtle movements. Nature 429:522.

He, Z., J. Eggert, W. Cheng, X. Zhao, J. Millspaugh, R. Moll, J. Beringer, and J. Sartwell. 2008. Energy-aware portable video communication system design for wildlife activity monitoring. IEEE Circuits and Systems 8:25-37.

Heithaus, M. R., and L. M. Dill. 2002. Food availability and tiger shark predation risk influence bottlenose dolphin habitat use. Ecology 83:480491.

Heithaus, M. R., J. J. McLash, A. Frid, L. M. Dill, and G. J. Marshall. 2002. Novel insights into green sea turtle behavior using animal-borne video cameras. Journal of Marine Biology Association of U.K. 82:10491050.

Johnson, B. K., T. McCoy, C. O. Kochanny, and R. C. Cook. 2006. Evaluation of vaginal implant transmitters in elk (Cervus elaphus nelsoni). Journal of Zoo and Wildlife Medicine 37:301-305.

Krausman, P. R., V. C. Bleich, J. W. Cain, III, T. R. Stephenson, D. W. DeYoung, P. W. McGrath, P. K. Swift, B. M. Pierce, and B. D. Jansen. 2004. From the field: neck lesions in ungulates from collars incorporating satellite technology. Wildlife Society Bulletin 32:987-991.

Littell, R. C., P. R. Henry, and C. B. Ammerman. 1998. Statistical analysis of repeated measures data using SAS procedures. Journal of Animal Science 76:1216-1231.

Marshall, G. J. 1998. Crittercam: an animal-borne imaging and data logging system. Marine Technology Society Journal 32:11-17.

Millspaugh, J. J., and B. E. Washburn. 2003. Within-sample variation of fecal glucocorticoid measurements. General and Comparative Endocrinology 132:21-26.

Millspaugh, J. J., and B. E. Washburn. 2004. Use of fecal glucocorticoid metabolite measures in conservation biology research: considerations for application and interpretation. General and Comparative Endocrinology 138:189-199.

Millspaugh, J. J., B. E. Washburn, M. A. Milanick, J. Beringer, L. P.
Hansen, and T. M. Meyer. 2002. Non-invasive techniques for stress assessment in white-tailed deer. Wildlife Society Bulletin 30:899-907.

Millspaugh, J. J., R. J. Woods, K. E. Hunt, K. J. Raedeke, G. C. Brundige, B. E. Washburn, and S. K. Wasser. 2001. Fecal glucocorticoid assays and the physiological stress response in elk. Wildlife Society Bulletin 29:899907.

Minteer, B. A., and J. P. Collins. 2005. Why we need an "ecological ethics." Frontiers in Ecology and the Environment 3:332-337.

Moll, R. J. 2008. Development and evaluation of a terrestrial animal-borne video system for ecological research. Thesis, University of Missouri, Columbia, USA

Moll, R. J., J. J. Millspaugh, J. Beringer, J. Sartwell, and Z. He. 2007. A new 'view' of ecology and conservation through animal-borne video systems. Trends in Ecology and Evolution 22:660-668.

Nussberger, B., and P. Ingold. 2006. Effects of radio-collars on behaviour of alpine chamois Rupicapra rupicapra rupicapra. Wildlife Biology 12:339343.

Passaglia, C., F. Dodge, E. Herzog, S. Jackson, and R. Barlow. 1997. Deciphering a neural code for vision. Proceedings of the National Academy of Sciences of the USA. 94:12649-12654.

R Development Core Team. 2004. R: a language and environment for statistical computing. Version 1.9.1. R Foundation for Statistical Computing, Vienna, Austria.

Read, A. F., and J. S. Clark. 2006. The past 20 years of ecology and evolution. Trends in Ecology and Evolution 21:287.

Rittenhouse, C. D., J. J. Millspaugh, B. E. Washburn, and M. W. Hubbard. 2005. Effects of radio transmitters on fecal glucocorticoid metabolite levels of three-toed box turtles in captivity. Wildlife Society Bulletin 33:706-713.

Romero, L. M., J. M. Reed, and J. C. Wingfield. 2000. Effects of weather on corticosterone responses in wild free-living passerine birds. General and Comparative Endocrinology 118:113-122.

Ropert-Coudert, Y., and R. P. Wilson. 2005. Trends and perspectives in animal-attached remote sensing. Frontiers in Ecology and the Environment 3:437-444.

Rutz, C., L. A. Bluff, A. A. S. Weir, and A. Kacelnik. 2007. Video cameras on wild birds. Science 318:765

SAS Institute. 2004. Base SAS 9.1 procedures guide, volumes 1-4. SAS, Cary, North Carolina, USA.

Schulz, J. H., J. J. Millspaugh, B. E. Washburn, A. J. Bermudez, J. L. Tomlinson, T. W. Mong, and Z. He. 2005. Physiological effects of radiotransmitters on mourning doves. Wildlife Society Bulletin 33:10921100 .

Schwarzenberger, F., E. Möstl, E. Bamberg, J. Pammer, and O. Schmehlik. 1991. Concentrations of progestagens and oestrogens in the faeces of pregnant Lipizzan, trotter and thoroughbred mares. Journal of Reproduction and Fertility Supplement 44:489-499.

Swenson, J. E., K. Wallin, G. Ericsson, G. Cederlund, and F. Sandegren. 1999. Effects of ear-tagging with radiotransmitters on survival of moose calves. Journal of Wildlife Management 63:354-358.

Touma, C., N. Sachser, E. Möstl, and R. Palme. 2003. Effects of sex and time of day on metabolism and excretion of corticosterone in urine and feces of mice. General and Comparative Endocrinology 130:267-278.

Wasser, S. K., K. E. Hunt, J. L. Brown, K. Cooper, C. M. Crockett, U. Bechert, J. J. Millspaugh, S. Larson, and S. L. Monfort. 2000. A generalized fecal glucocorticoid assay for use in a diverse array of nondomestic mammalian and avian species. General and Comparative Endocrinology 120:260-275.

Wasser, S. K., S. Papageorge, C. Foley, and J. L. Brown. 1996. Excretory fate and metabolites of oestradiol and progesterone in the African elephant (Loxodonta africana) and patterns of fecal steroid concentrations throughout the estrous cycle. General and Comparative Endocrinology 102:255-262.

Wells, K. M. S., B. E. Washburn, J. J. Millspaugh, M. R. Ryan, and M. W. Hubbard. 2003. Effects of radio-transmitters on fecal glucocorticoid levels in captive dickcissels. Condor 105:805-810.

White, G. C., and R. A. Garrott. 1990. Analysis of wildlife radio-tracking data. Academic Press, New York, New York, USA.

Williams, T. M., R. W. Davis, L. A. Fuiman, J. Francis, B. J. Le Boeuf, M. 
Horning, J. Calambokidis, and D. A. Croll. 2000. Sink or swim: strategies for cost-efficient diving by marine mammals. Science 288:133136.

Wilson, R. P., and C. R. McMahon. 2006. Measuring devices on wild animals: what constitutes acceptable practice? Frontiers in Ecology and the Environment 4:147-154.
Withey, J. C., T. D. Bloxton, and J. M. Marzluff. 2001. Effects of tagging and location error in wildlife radiotelemetry studies. Pages 43-75 in J. J. Millspaugh and J. M. Marzluff, editors. Radio tracking and animal populations. Academic Press, San Diego, California, USA.

Associate Editor: Hall. 